\title{
Effects of the Fort McMurray wildfires on the health of evacuated workers: follow-up of 2 cohorts
}

\author{
Nicola Cherry MDCM, Whitney Haynes MPhil
}

\section{Abstract}

Background: Wildfire engulfed Fort McMurray, Alberta on May 3, 2016, leading to a total evacuation. Access to 2 active cohorts allowed us to rapidly assess health effects in those evacuated.

Methods: People working in Fort McMurray who had been recruited before the fire for 2 occupational health cohort studies completed a questionnaire (online or via telephone) 3-26 weeks after evacuation. The questionnaire asked about respiratory and mental health and experiences since the fire.

Results: Of the 129 participants, 109 were in the Fort McMurray area on May 3. Thirty-seven (33.9\%) of the participants who were in Fort McMurray on May 3 reported a health condition, including respiratory symptoms $(n=17)$ and mental ill health $(n=$ 17), immediately after the fire. At follow-up, a mean of 102 days after the fire, 11 participants (10.1\%) reported a fire-related health condition, including mental ill health $(n=8)$ and respiratory symptoms $(n=2)$. There was no difference before and after the fire in use of alcohol, cigarettes, recreational drugs or medication. One in 4 participants (32 [24.6\%]) had not worked since the fire, and fewer than half (58 [44.6\%]) had returned to Fort McMurray. Of the 90 participants evacuated, 15 (16.7\%) had scores indicative of moderate or severe anxiety or depression on the Hospital Anxiety and Depression Scale. Those evacuated had significantly higher mean anxiety $(p=0.01)$ and depression $(p=0.04)$ scores than those not evacuated. Regression modelling showed that anxiety scores were higher for women, with longer time since the fire and with evacuation to a motel. Depression scores were higher for women and with financial loss because of lack of work.

Interpretation: Although evacuation was associated with higher anxiety and depression scores, persisting ill health was not widespread at early follow-up after the fire. Although these results are encouraging, these "healthy worker" results cannot be generalized to all evacuees.

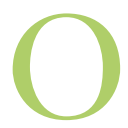

n May 3, 2016, wildfires engulfed Fort McMurray, located in northern Alberta. A total evacuation of some 88000 civilians was carried out, with the loss of only 2 lives in a vehicle collision. About 2400 homes and other buildings were destroyed. A fluctuating population of roughly 20000 living in work camps was also threatened by the fire. Apart from a personal account of the evacuation of the hospital, ${ }^{1}$ we are not aware of any publication on the health impacts of the fire. Previous investigations of disasters in Canada have not focused on workers. ${ }^{2,3}$

We report a study among workers recruited before the fire to 2 cohorts, 1 of workers in a prospective study of work injuries in the Fort McMurray/Wood Buffalo area (referred to from here on as Fort McMurray) and the other of men and women in the welding and electrical trades, which are in high demand in the oil fields, for which Fort McMurray is the hub. Many workers come to the region from across Canada because of the opportunity to earn high wages. Some continue to commute back to families elsewhere, and others come to regard Fort McMurray as home. Our existing cohorts provided a unique opportunity to assess rapidly the early effects of the fire. The chance existence of a preexisting cohort, as with the Canterbury earthquakes ${ }^{4}$ provides a powerful research design that minimizes bias. The sample is selected before residents are widely dispersed, the decision to take part is independent of health status after the event, commitment to the research before the disaster enhances participation, and collection of health indicators before the event facilitates analysis of change and susceptibility.

\section{Competing interests: None declared.}

This article has been peer reviewed.

Correspondence to: Nicola Cherry, ncherry@ualberta.ca

CMAJ Open 2017. DOI:10.9778/cmajo.20170047 
The members of our cohorts do not represent everyone in the Fort McMurray area on May 3, but together they are a sample, not biased by events since the fire, of both the settled and more transient workers whose lives have been dislocated. We wanted to know whether the fire had affected their mental and physical health and, if so, whether these effects had been mitigated or exacerbated by events at the time of evacuation and in the following days and weeks.

\section{Methods}

\section{Setting}

Information was collected from workers believed to be in Fort McMurray on May 3, 2016.

\section{Participants}

A postfire study group was created that included workers based in Fort McMurray who had been recruited before the fire for 2 occupational health cohort studies, described more fully in Appendix 1 (available at www.cmajopen.ca/content/5/3/E638/ suppl/DC1) (Figure 1). Most participants in the postfire study group were from a study of occupational injury (Table 1). All those in the injury study were working in Fort McMurray at the time of their recruitment, completed on Apr. 29, 2016. This injury cohort comprised workers who were resident in Fort McMurray and also those who were more transient, working in the area but maintaining a home elsewhere. A smaller number of participants in the postfire study group were from an ongoing nationwide cohort of women and men in the welding and elec- trical trades. ${ }^{5,6}$ As it seemed likely that some of these people would be working in Fort McMurray, we emailed them all $(n=$ 1883) and asked them to contact us if they had been in Fort McMurray at the time of the fire. Recruitment from this second cohort included many who were living in work camps, which increased the representativeness of the study group, giving it a profile more similar to that of the working population of the Fort McMurray area as a whole.

The postfire study group is thus essentially a convenience sample of workers we were able to contact and for whom we had information before the fire, collected as part of 2 independent studies. It is not a representative sample selected specifically for this study.

\section{Data collection}

For all participants in the postfire study group, we had demographic, health and substance use information, collected before the fire. After the fire, participants were asked to complete, by telephone or online, an additional questionnaire focused on events and health during and since the fire. The questionnaire (Appendix 2, available at www. cmajopen.ca/content/5/3/E638/suppl/DC1) was devised specifically for this study and incorporated questions used in the injury and trades cohort studies. The timing of administration of the postfire questionnaire was determined by the nature of the most recent contact before the fire (Table 1). No contact attempt was made during the first 14 days after evacuation. Workers from the injury cohort who had already completed an injury follow-up

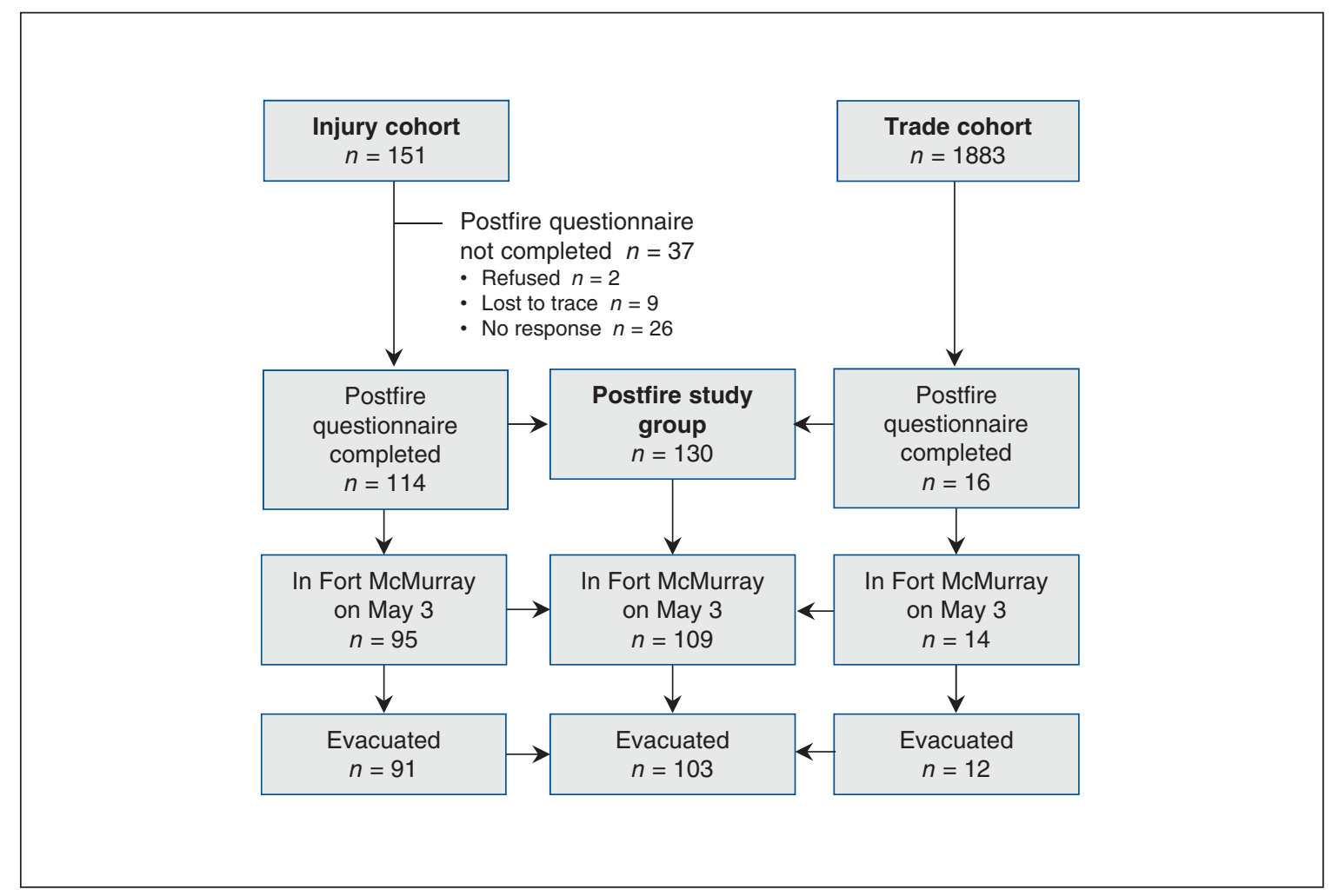

Figure 1: Flow diagram for evacuation within the postfire study group. 


\begin{tabular}{|c|c|c|c|c|c|c|}
\hline \multicolumn{7}{|c|}{ Table 1: Data collection } \\
\hline $\begin{array}{l}\text { Cohort of } \\
\text { origin }\end{array}$ & $\begin{array}{l}\text { Questionnaire } \\
\text { completed before fire }\end{array}$ & $\begin{array}{c}\text { No. of } \\
\text { workers }\end{array}$ & $\begin{array}{c}\text { No. } \\
\text { evacuated }\end{array}$ & $\begin{array}{l}\text { Mean time to } \\
\text { completion of } \\
\text { postfire } \\
\text { questionnaire } \\
\text { (range), } d^{*}\end{array}$ & Method & Data not collected \\
\hline Injury & Baseline only & 89 & 71 & $115.1(20-181)$ & Online/telephone & - \\
\hline Trades & $\begin{array}{l}\text { Baseline and multiple } \\
\text { follow-up }\end{array}$ & 16 & 12 & $79.9(23-168)$ & Telephone & $\begin{array}{l}\text { No anxiety and } \\
\text { depression scores } \\
\text { No data on use of } \\
\text { recreational drugs }\end{array}$ \\
\hline
\end{tabular}

questionnaire were then asked to complete an additional, postfire questionnaire. Those who, at the time of the fire, had not yet completed the injury follow-up questionnaire were approached to do so 16 weeks after recruitment, the time determined by the protocol for that study; they completed the postfire questionnaire as well. Workers from the trades cohort were requested to complete the postfire questionnaire as soon as they informed us that they had been in Fort McMurray (either in response to a "one-off" email sent to all cohort members or at the next scheduled followup interview). Participants from the injury cohort were given the choice of completing the questionnaire online or by telephone, whereas all interviews for those from the trades cohort were by telephone.

The questionnaire was essentially the same for all participants except that the Hospital Anxiety and Depression Scale, a widely used 14-item questionnaire found to perform well in screening for "caseness" that was part of the end-of-study assessment in the trades cohort, was not used in that cohort (Table 1).

The following information was available for analysis:

- Outcome variables: self-reported health problems during or immediately after the fire and at follow-up; change from prefire data on use of alcohol, tobacco, recreational drugs or physician-prescribed medication; for participants from the injury cohort, score at follow-up on the Hospital Anxiety and Depression Scale

- Demographic factors before the fire: sex, age, occupation (skilled/other), permanent home in Fort McMurray, married, number of children

- Health before the fire: medications (and why taken) in the previous week

- Events at the time of the fire: presence in Fort McMurray, whether evacuated, direction of evacuation (north or south), sleeping arrangements during the first couple of days after the fire

- Events since the fire: damage to own neighbourhood, financial loss (property damage/lack of work), resumption of paid employment, residence in Fort McMurray at follow-up.

\section{Statistical analysis}

We tabulated demographic, health, event and outcome data, and compared use of medication, tobacco, alcohol and recreational drugs before and after the fire. For participants from the injury cohort, we evaluated differences in mean anxiety and depression scores between those who were evacuated and those who were not evacuated by analysis of variance, and calculated the proportions with moderate or high scores (using the cut-points recommended in the Hospital Anxiety and Depression Scale manual). We examined the determinants of anxiety and depression scores by computing mean Hospital Anxiety and Depression Scale scores for each demographic, fire-related and postfire factor. All variables with a difference between categories likely to arise by chance with $p<0.10$ were retained and entered into multivariable regression models with anxiety and depression scores as the dependent variables. We determined the final model for association with anxiety and depression using a forward stepwise model in which variables (with $p<0.05$ ) were entered sequentially after allowance for more strongly related variables.

\section{Ethics approval}

Ethics approval was obtained from the University of Alberta Health Ethics Board.

\section{Results}

There were 130 participants in the postfire study group, $114 / 151(75.5 \%)$ of those in the injury cohort and $16 / 1883$ $(0.8 \%)$ of those in the trades cohort. Of the 130,109 (95 from the injury cohort and 14 from the trades cohort) were present in the Fort McMurray area on May 3. The data for 1 participant from the injury cohort whose whereabouts were unclear were excluded from the analysis of the effects of the evacuation (Figure 1).

The demographic characteristics of the participants are shown in Table 2 . The 2 contributing cohorts were similar in age and sex but differed in residency: fewer than 1 in 5 participants from the trades cohort had established their home in 
Table 2: Characteristics of participants

\begin{tabular}{|c|c|}
\hline Characteristic & $\begin{array}{l}\text { No. }(\%) \text { of } \\
\text { participants }\end{array}$ \\
\hline \multicolumn{2}{|l|}{ Demographic $(n=130)$} \\
\hline \multicolumn{2}{|l|}{ Sex } \\
\hline Male & $81(62.3)$ \\
\hline Female & $49(37.7)$ \\
\hline \multicolumn{2}{|l|}{ Age, yr } \\
\hline$\leq 25$ & $21(16.2)$ \\
\hline $26-35$ & $39(30.0)$ \\
\hline $36-45$ & $29(22.3)$ \\
\hline $46-66$ & $41(31.5)$ \\
\hline Working in skilled trade & $53(40.8)$ \\
\hline Home established in Fort McMurray & $77(59.2)$ \\
\hline Married/living as married & $54(41.5)$ \\
\hline$\geq 1$ child & $50(38.5)$ \\
\hline \multicolumn{2}{|l|}{$\begin{array}{l}\text { Events during fire among those } \\
\text { evacuated }(n=103)\end{array}$} \\
\hline \multicolumn{2}{|l|}{ Initial direction of evacuation } \\
\hline North & $30(29.1)$ \\
\hline South & $73(70.9)$ \\
\hline \multicolumn{2}{|l|}{ Sleeping arrangements* } \\
\hline Vehicle, recreational vehicle or trailer & $39(37.9)$ \\
\hline Reception centre & $4(3.9)$ \\
\hline Motel/hotel & $24(23.3)$ \\
\hline Work camp & $21(20.4)$ \\
\hline Friends/family & $25(24.3)$ \\
\hline Own home & $11(10.7)$ \\
\hline Other & $3(2.9)$ \\
\hline \multicolumn{2}{|l|}{ Events since fire $(n=130)$} \\
\hline \multicolumn{2}{|l|}{ Damage to own neighbourhood } \\
\hline Yes & $25(19.2)$ \\
\hline No & $61(46.9)$ \\
\hline Not known & $9(6.9)$ \\
\hline Not identified with neighbourhood & $35(26.9)$ \\
\hline \multicolumn{2}{|l|}{ Financial loss from property damage } \\
\hline Yes & $25(19.2)$ \\
\hline No & $97(74.6)$ \\
\hline Not known & $8(6.2)$ \\
\hline Financial loss from work & $70(53.8)$ \\
\hline Paid work since fire & $98(75.4)$ \\
\hline Living in Fort McMurray at follow-up & $58(44.6)$ \\
\hline
\end{tabular}

Fort McMurray, whereas two-thirds of those from the injury cohort had done so. A total of 29 (26.6\%) of the 109 participants in Fort McMurray on May 3 were living in a work camp, including 11 of those from the trades cohort.

\section{Experience at and since the time of the fire}

Of the 109 participants in Fort McMurray on May 3, all but 6 (5 living in a camp outside the immediate fire zone and 1 first responder) were evacuated (Table 2). Of the 103 evacuees, 73 $(70.9 \%)$ went south, toward major conurbations. Few reception centres were operating, and people slept in their vehicle or in recreational vehicles, found motel rooms or went to friends or family. About 1 in 5 were evacuated to work camps north of Fort McMurray, and a few made their way to their own home.

Of the 130 participants, $25(19.2 \%)$ reported that there had been damage to their own neighbourhood in Fort McMurray, and 9 (6.9\%) did not yet know about damage (Table 2). Similar numbers reported financial loss from property damage. More than half (70 [53.8\%]) reported financial loss from lack of work. One in 4 (32 [24.6\%]) had not held paid work since the fire, and fewer than half (58 [44.6\%]) had returned to Fort McMurray, although 112 (89.6\%) of the 125 participants wanting to work planned to do so there.

\section{Health effects}

Thirty-seven $(33.9 \%)$ of the 109 participants who were in Fort McMurray on May 3 reported that their health had been affected during or immediately after the fire. Respiratory symptoms $(n=17)$ were reported most frequently, followed by mental ill health $(n=15)$ (Table 3$)$. Three of the 6 participants not evacuated reported respiratory symptoms at the time of the fire, and none reported mental ill health. At follow-up, the number with health issues attributed to the fire had decreased to $11(10.1 \%)$, with mental ill-health being reported more frequently than respiratory symptoms.

A total of 38 participants (34.9\%) reported in their most recent prefire questionnaire that they had taken medication during the previous week. Three (42.8\%) of the 7 taking medication for asthma and/or mental ill health before the fire had persistent health problems at follow-up, compared to $8(7.8 \%)$ of the 102 not taking medication for either of these conditions $(p=0.02)$.

There was no increase in the number taking medication after the fire (35 [32.1\%]).

Among the evacuated participants $(n=87$ for whom data on use were available), no change was seen in the use of alcohol or cigarettes. Fifty-five (63\%) reported drinking in the last month before the fire, compared with 53 (61\%) after the fire; the mean number of drinks/week before and after the fire was 5.5 and 5.3, respectively. Thirty participants (34\%) reported smoking before the fire, compared with 31 (36\%) after the fire; the mean number of cigarettes/day was 12.6 and 12.9, respectively. There was no difference in recreational drug use before and after the fire $(11 / 73[15 \%]$ v. $7 / 73[10 \%])$.

\section{Anxiety and depression scores}

Of the 112 participants from the injury cohort with Hospital Anxiety and Depression Scale scores, 90 were evacuated from Fort McMurray, and 22 were not evacuated or were not in Fort McMurray on May 3 (Table 4). Those evacuated had significantly higher mean anxiety scores $(p=0.01)$ and depression scores $(p=0.04)$ than those not evacuated. Fifteen $(16.7 \%)$ of those evacuated had scores suggestive of moderate 


\begin{tabular}{|c|c|c|c|c|c|c|c|c|c|}
\hline \multirow[b]{2}{*}{$\begin{array}{l}\text { Health problem at time } \\
\text { of fire }\end{array}$} & \multicolumn{9}{|c|}{ Health problem at follow-up; no. of participants } \\
\hline & $\begin{array}{c}\text { No } \\
\text { problem }\end{array}$ & Problem & All & $\begin{array}{c}\text { No } \\
\text { problem }\end{array}$ & Problem & All & $\begin{array}{c}\text { No } \\
\text { problem }\end{array}$ & Problem & All \\
\hline Respiratory & 13 & 1 & 14 & 2 & 1 & 3 & 15 & 2 & 17 \\
\hline Mental health & 7 & 8 & 15 & 0 & 0 & 0 & 7 & 8 & 15 \\
\hline Other & 4 & 1 & 5 & 0 & 0 & 0 & 4 & 1 & 5 \\
\hline Total & 93 & 10 & 103 & 5 & 1 & 6 & 98 & 11 & 109 \\
\hline
\end{tabular}

\begin{tabular}{|c|c|c|c|}
\hline \multirow[b]{2}{*}{ Variable } & \multirow{2}{*}{$\begin{array}{c}\text { No. of } \\
\text { participants }\end{array}$} & \multicolumn{2}{|c|}{ Mean score \pm SD } \\
\hline & & Anxiety & Depression \\
\hline \multicolumn{4}{|l|}{ In Fort McMurray on May 3} \\
\hline Evacuated & $90^{*}$ & $6.3 \pm 4.5$ & $4.1 \pm 4.0$ \\
\hline Not evacuated & 4 & $1.8 \pm 1.3$ & $2.0 \pm 1.4$ \\
\hline $\begin{array}{l}\text { Based in Fort McMurray but } \\
\text { not there May } 3\end{array}$ & 11 & $3.9 \pm 3.7$ & $2.8 \pm 2.9$ \\
\hline $\begin{array}{l}\text { No longer living/working in Fort } \\
\text { McMurray }\end{array}$ & 7 & $3.6 \pm 2.1$ & $1.6 \pm 1.4$ \\
\hline Total & 112 & $4.4 \pm 3.9$ & $3.7 \pm 3.8$ \\
\hline All not evacuated & 22 & $3.4 \pm 2.9$ & $2.3 \pm 2.5$ \\
\hline Compared with evacuated & & $p=0.01$ & $p=0.04$ \\
\hline
\end{tabular}

or severe anxiety or depression at follow-up (Table 5). None of the 22 participants not evacuated had a score indicating moderate or severe anxiety or depression.

We computed mean anxiety and depression scores for each of the factors shown in Table 2 and Table 3. The mean scores for factors for which the probability that a difference between means would arise by chance was $<0.10$ are shown in Table 6. Of the variables in Table 2, only sex met this criterion, with anxiety and depression scores higher among women than among men. Only evacuation to a reception centre or motel was related to a higher anxiety score. Participants also had higher mean anxiety scores if their neighbourhood had been damaged by the fire (or if this was still uncertain), if they had financial loss from lack of work or if they reported health problems immediately after the fire. For depression scores, only sex and financial loss from lack of work met the criterion. The time between the fire and the date of questionnaire completion is also shown, with anxiety scores being higher (although not statistical significantly so) for those who completed the questionnaire more than 3 months after the fire.
When the variables in Table 6 were entered into a single multiple regression model, only 3 factors - being female, evacuation to a motel and time since the fire - appeared to be independently related $(p<0.10)$ to anxiety score (Table 7$)$. Depression score was related only to being female and to financial loss. These factors were confirmed in the final stepwise models $(p<0.05)$ (Table 7).

\section{Interpretation}

In this group of people who had been working in the Fort McMurray area at the time of the wildfire, there was limited evidence of sustained mental or physical ill health attributable to the fire at early follow-up (mean $102 \mathrm{~d}$ among those evacuated). Among participants who recalled immediate health effects of the fire, mental ill health was more likely to persist at follow-up than were respiratory symptoms. Only small numbers were taking medication for mental ill health or asthma before the fire, but these participants were more likely than than those not taking such medications to have symptoms at follow-up. There was no evidence of increased use of 
alcohol, tobacco, recreational drugs or prescribed medication after the fire. Nevertheless, those who had been evacuated had significantly higher anxiety and depression scores than those not evacuated. Anxiety scores were higher among women, those evacuated to a motel, and those who completed the questionnaire more than 3 months after the fire. Depression

\begin{tabular}{|c|c|c|c|c|c|}
\hline \multirow[b]{2}{*}{ Anxiety score } & \multicolumn{5}{|c|}{ Depression score } \\
\hline & $\begin{array}{c}\text { No concern } \\
(1-7)\end{array}$ & $\begin{array}{l}\text { Mild } \\
(8-11)\end{array}$ & $\begin{array}{c}\text { Moderate } \\
(12-14)\end{array}$ & $\begin{array}{l}\text { Severe } \\
(15-30)\end{array}$ & Total \\
\hline No concern (1-7) & 52 & 3 & 1 & 0 & 56 \\
\hline Mild (8-11) & 17 & 3 & 2 & 1 & 23 \\
\hline Moderate (12-14) & 4 & 1 & 0 & 1 & 6 \\
\hline Severe $(15-30)$ & 1 & 2 & 1 & 1 & 5 \\
\hline Total & 74 & 9 & 4 & 3 & 90 \\
\hline
\end{tabular}

\begin{tabular}{|c|c|c|c|c|c|}
\hline \multirow[b]{2}{*}{ Variable } & \multirow[b]{2}{*}{$\begin{array}{c}\text { No. of } \\
\text { participants }\end{array}$} & \multicolumn{2}{|c|}{ Anxiety } & \multicolumn{2}{|c|}{ Depression } \\
\hline & & $\begin{array}{c}\text { Mean score } \\
\pm \text { SD }\end{array}$ & $p$ value & $\begin{array}{c}\text { Mean score } \\
\pm \text { SD }\end{array}$ & $p$ value \\
\hline \multicolumn{6}{|l|}{ Sex } \\
\hline Male & 54 & $5.3 \pm 4.4$ & 0.01 & $3.4 \pm 3.7$ & 0.04 \\
\hline Female & 36 & $7.8 \pm 5.2$ & & $5.2 \pm 5.2$ & \\
\hline \multicolumn{6}{|c|}{ First evacuation nights } \\
\hline \multicolumn{6}{|c|}{ Reception centre } \\
\hline Yes & 4 & $10.3 \pm 6.2$ & 0.07 & $5.5 \pm 7.1$ & 0.48 \\
\hline No & 86 & $6.1 \pm 4.3$ & & $4.1 \pm 3.9$ & \\
\hline \multicolumn{6}{|l|}{ Motel } \\
\hline Yes & 23 & $8.2 \pm 5.5$ & 0.02 & $5.0 \pm 4.5$ & 0.25 \\
\hline No & 67 & $5.6 \pm 3.9$ & & $3.8 \pm 3.8$ & \\
\hline \multicolumn{6}{|c|}{ Neighbourhood damaged } \\
\hline Yes/unknown & 27 & $7.5 \pm 5.7$ & 0.10 & $4.9 \pm 4.7$ & 0.24 \\
\hline No & 63 & $5.7 \pm 3.8$ & & $3.8 \pm 3.7$ & \\
\hline \multicolumn{6}{|c|}{$\begin{array}{l}\text { Financial loss from lack of } \\
\text { work }\end{array}$} \\
\hline Yes & 27 & $7.0 \pm 4.7$ & 0.07 & $4.8 \pm 4.1$ & 0.06 \\
\hline No & 63 & $5.4 \pm 4.0$ & & $3.3 \pm 3.7$ & \\
\hline \multicolumn{6}{|c|}{$\begin{array}{l}\text { Health problem immediately } \\
\text { after fire }\end{array}$} \\
\hline Yes & 30 & $7.6 \pm 4.3$ & 0.06 & $5.0 \pm 4.0$ & 0.13 \\
\hline No & 60 & $5.7 \pm 4.5$ & & $3.7 \pm 4.0$ & \\
\hline \multicolumn{6}{|c|}{$\begin{array}{l}\text { Length of time to } \\
\text { questionnaire completion, } d\end{array}$} \\
\hline$\leq 91$ & 36 & $6.9 \pm 4.9$ & 0.14 & $4.2 \pm 4.1$ & 0.77 \\
\hline $92-182$ & 54 & $5.4 \pm 3.7$ & & $4.0 \pm 3.9$ & \\
\hline Overall & 90 & $6.3 \pm 45$ & & $4.1 \pm 4.0$ & \\
\hline
\end{tabular}




\begin{tabular}{|c|c|c|c|c|}
\hline \multirow[b]{2}{*}{ Variable } & \multicolumn{2}{|c|}{ Anxiety score } & \multicolumn{2}{|c|}{ Depression score } \\
\hline & $\beta$ & $p$ value & $\beta$ & $p$ value \\
\hline \multicolumn{5}{|l|}{ All variables entered at 1 step } \\
\hline Male sex & -0.29 & 0.01 & -0.20 & 0.07 \\
\hline $\begin{array}{l}\text { Evacuated to reception } \\
\text { centre }\end{array}$ & 0.12 & 0.22 & 0.04 & 0.73 \\
\hline Evacuated to motel & 0.25 & 0.01 & 0.09 & 0.43 \\
\hline Neighbourhood damage & 0.10 & 0.32 & 0.11 & 0.34 \\
\hline Financial loss from work & 0.15 & 0.15 & 0.21 & 0.06 \\
\hline Health problem after fire & 0.11 & 0.27 & 0.12 & 0.30 \\
\hline$>90 \mathrm{~d}$ since fire & 0.18 & 0.09 & 0.01 & 0.91 \\
\hline \multicolumn{5}{|l|}{$\begin{array}{l}\text { Variables entered stepwise, } \\
\text { with most strongly related } \\
\text { entered first }\end{array}$} \\
\hline Male sex & -0.34 & 0.00 & -0.21 & 0.04 \\
\hline Evacuated to motel & 0.31 & 0.00 & - & - \\
\hline$>90 \mathrm{~d}$ since fire & 0.26 & 0.01 & - & - \\
\hline Financial loss from work & - & - & 0.21 & 0.05 \\
\hline
\end{tabular}

scores, which were also higher among women, were associated with financial loss from lack of work.

In putting these results into context it must be recalled that the people living and working in the Fort McMurray area were evacuated rapidly and that, although the density of the smoke and the proximity and ferocity of the fire were terrifying to many, the acute exposure was time-limited: those evacuated were out of the fire zone within 24 hours. As such, any effects on the respiratory system might be expected to be transitory and largely exacerbations of preexisting conditions. ${ }^{8}$

Effects on mental health would be expected to reflect both the stresses of the evacuation itself and subsequent events. Authors of reviews of earlier studies have concluded that most people exposed to natural catastrophes are resilient. ${ }^{9-11}$ For example, 2-4 years after the Black Sunday wildfires in Victoria, Australia, in which there were 173 fatalities and massive infrastructure disruption, even in the worst-affected area fewer than 1 in 4 people were found to have indicators of psychological distress. ${ }^{12}$ The observed low proportion of participants with scores indicating moderate or severe anxiety or depression in the current study is in line with these findings. However, the length of follow-up may have been too short to reflect the full extent of disturbance. Mean anxiety scores were higher in those interviewed more than 3 months after the fire than in those interviewed earlier, and previous studies suggest that primary referrals for psychological disturbance may peak toward the end of the first year after a calamitous event. ${ }^{13,14}$ Furthermore, posttraumatic stress disorder may have a delayed onset or increase in severity over time. ${ }^{15,16}$ Data are available on physician visits throughout Alberta for all those (not just workers) normally resident in Fort McMur- ray. ${ }^{17}$ Compared to the first week in December 2015 (before the fire), in the same week in 2016 (9 mo after the fire), physician visits for anxiety increased by $14 \%$ and for depression by $28 \%$, whereas visits for substance use disorder decreased markedly. We found no increase in substance use after the fire, although this might have been expected. ${ }^{18}$ Although there are studies of the effects on later mental ill health of physical barriers to evacuation, ${ }^{19}$ we did not find studies that systematically examined the effects on later ill health of logistical arrangements during evacuation, although family separation has been identified as an important stressor. ${ }^{20}$ In the present study, those accommodated in motels were largely long-term residents of Fort McMurray who did not find accommodation with family or friends; a motel may have been only the first stage in a longer period of unsettled housing.

\section{Limitations}

Limitations of this study include the lack of good denominator data for the trades cohort (we do not know how many of the 1883 workers in that cohort were in the Fort McMurray area at the time of the fire), the possibility of bias in the recall of health effects during or immediately after the fire, and the likely unrepresentativeness of our convenience sample. Our participants were all employed and were generally fit, and few had chronic ill health. As such, their resilience may be greater than that of other civilians involved in the evacuation, and we cannot generalize our results to those not in paid employment, to other age groups or to first responders. Even among employed people, some will have been underrepresented, as our recruitment methods would have effectively excluded those working within Indigenous communities. Permanent 
employees of large companies may have had different experiences after the fire than those in more precarious work. A further limitation is that our conclusion that the evacuation increased both anxiety and depression scores rests on comparison with those who by chance or choice were not in the area of the fire on May 3. The staggered timing of data collection after the fire (20-181 days) reflects the protocols for the cohort studies from which the study group was drawn. Although this has some disadvantages, such as introducing different periods of recall and varying times to reestablish employment, it also provided an important opportunity to examine the evolution of mental health during the postfire period.

\section{Conclusion}

The conclusions from this study are guardedly optimistic. Although some participants may need support for mental ill health going forward, the results of this and earlier studies suggest that most of these workers will successfully reestablish their lives, with most hoping to return to work in the Fort McMurray area. Financial loss from lack of work was the major cause of depression, and for these workers an upturn in investment and in the local economy is probably the single factor most likely to support recovery.

\section{References}

1. Sauve M. City on fire. Ann Intern Med 2017;166:373-5.

2. King S, Laplante DP. The effects of prenatal maternal stress on children's cognitive development: Project Ice Storm. Stress 2005;8:35-45.

3. Kulig J, Botey AP. Facing a wildfire: What did we learn about individual and community resilience? Nat Hazards 2016;82:1919-29.

4. Fergusson DM, Horwood LJ, Boden JM, et al. Impact of a major disaster on the mental health of a well-studied cohort. 7AMA Psychiatry 2014;71: 1025-31.

5. Arrandale VH, Beach J, Cembrowski GS, et al. Urinary metal concentrations among female welders. Ann Occup Hyg 2015;59:52-61.

6. Cherry N, Beach J, Galarneau JM, et al. Women (and men) in the welding trades: an update on the WHAT-ME and WHAT-MEN projects. Can Welding Assoc 7 2017;20:46-51.

7. Bjelland I, Dahl AA, Haug TT, et al. The validity of the Hospital Anxiety and Depression Scale: an updated literature review. 7 Psychosom Res 2002;52: 69-77.

8. Reid CE, Brauer M, Johnston FH, et al. Critical review of health impacts of wildfire smoke exposure. Environ Health Perspect 2016;124:1334-43.
9. Fergusson DM, Boden JM. The psychological impacts of major disasters. Aust N Z 7 Psychiatry 2014;48:597-9.

10. Norris FH, Friedman MJ, Watson PJ, et al. 60000 disaster victims speak: Part 1. An empirical review of the empirical literature, 1981-2001. Psychiatry 2002;65:207-39

11. Neria Y, Nandi A, Galea S. Post-traumatic stress disorder following disasters a systematic review. Psychol Med 2008;38:467-80.

12. Bryant RA, Waters E, Gibbs L, et al. Psychological outcomes following the Victorian Black Saturday bushfires. Aust N Z 7 Psychiatry 2014;48:634-43.

13. Reifels L, Bassilios B, Spittal MJ, et al. Patterns and predictors of primary mental health service use following bushfire and flood disasters. Disaster Med Public Health Prep 2015;9:275-82.

14. Norris FH, Elrod C. Psychosocial consequences of disaster: a review of past research. In: Norris FH, Galea S, Friedman M, et al., editors. Methods for disaster mental health research. New York: Guilford; 2006:20-44.

15. Utzon-Frank N, Breinegaard N, Bertelsen M, et al. Occurrence of delayedonset post-traumatic stress disorder: a systematic review and meta-analysis of prospective studies. Scand $\mathcal{F}$ Work Environ Health 2014;40:215-29.

16. Neria Y, DiGrande L, Adams BG. Posttraumatic stress disorder following the September 11, 2001, terrorist attacks: a review of the literature among highly exposed populations. Am Psychol 2011;66:429-46.

17. Alberta Health Services, Interactive Health Data Application (IHDA), Health Service Utilization, Fort McMurray Wildfire Surveillance - Physician Services. Available: http://ahw.gov.ab.ca/IHDA_Retrieval/ihdaData.do (accessed 2017 Aug. 10).

18. Vlahov D, Galea S, Resnick H, et al. Increased use of cigarettes, alcohol and marijuana among Manhattan, New York residents after the September 11th terrorist attacks. Am 7 Epidemiol 2002;155:988-96.

19. Sherman MF, Gershon RR, Riley HEM, et al. Emergency preparedness safety climate and other factors associated with mental health outcomes among World Trade Center disaster evacuees. Disaster Med Public Health Prep 2017;11:326-36

20. Gallagher HC, Richardson J, Forbes D, et al. Mental health following separation in a disaster: the role of attachment. 7 Trauma Stress 2016;29:56-64.

Affiliation: Division of Preventive Medicine (Cherry, Haynes), University of Alberta, Edmonton, Alta.

Contributors: Nicola Cherry conceived and designed the study, analyzed the data and drafted the article. Whitney Haynes contributed substantially to the acquisition, analysis and interpretation of the data and revised the article critically for important intellectual content. Both authors approved the final version to be published and agreed to act as guarantors of the work.

Funding: Both cohorts are supported with funds from the OHS (Occupational Health and Safety) Futures program of the Alberta Government. The study of women in trades is also funded by the Canadian Institutes of Health Research.

Supplemental information: For reviewer comments and the original submission of this manuscript, please see www.cmajopen.ca/content/5/3/ E638/suppl/DC1. 